\title{
Research on China's Sports Nutrition Industry Food Development
}

\author{
Huawei Liang*
}

Institute of P.E., Henan Polytechnic University, Shanyang, P.R. China

\begin{abstract}
China has changed from the surviving stage to the developing stage. In developing stage, the demand for life quality has increased, more and more people are participating in sports, thus new challenges has presented themselves in the development of sports nutrition industry. This paper uses research methods such as literature research, field research, case study, comparative study and others, in depth analyzes China' s sports nutrition industry, reaches conclusions as follows: First, the market demand of China's sports nutrition industry is insufficient. Second, the number of the suppliers of sports nutrition in the market and the size of sports nutrition market are relatively small. Third, from perspectives of market concentration rate, barriers to entry and products differentiation, the current market structure of China's sports nutrition industry is oligopoly. However, accompanied by the increase of number of competitors in the market and the expansion of the market size; the market structure will shift to monopolistic competition. Fourth, the experiences of western countries in research of sports nutrition, successful marketing strategy and strict governmental supervision and regulation will provide important reference in the development of China's sports nutrition industry. Based on the conclusions above, this paper proposes the strategy thinking and suggestions for the development of China's sports nutrition industry as follows: first, implementing the strategic restructuring. Second, it can enhance the research arid development of technology. Third, the brand is built. Fourth, the government should conduct system reform to ensure orderly competition and healthy development of sports nutrition industry by supervision and regulations.
\end{abstract}

Keywords: Sports nutrition, industry, development, acid, technology.

\section{INTRODUCTION}

Since reform and opening up, Chinese economy has kept a rapid growth speed. Especially during the "eleventh five year plan", the average annual increase of GDP is $10.7 \%$, much higher than $3.9 \%$, the global economic growth of the corresponding period. Nowadays china's gross domestic product per capita has been more than 5000 dollars, that is, according to the criteria of the World Bank, china has entered the ranks of Middle-income countries. On the whole, China has changed from surviving stage into developing stage, thus the consumption structure and consumption pattern changed accordingly. The main purpose of developing stage is to promote human beings' development in an allaround way. In this sense, health is essentially important, since it is the life basis, necessary means and fundamental approach for human society's progress.

After the 2008 Beijing Olympic Games, the public participate in sports more actively and more social groups are involved, which provides both valuable opportunities and new challenges for the development of China's sports nutrition industry.

China's sports nutrition food industry originated from the demand of increasing performance in competitive sports. The consumer group is mainly professional athletes then. Therefore, the sports nutrition food industry was seen as niche market during that period. However, with the shift of situation, the industry has changed from niche market to mass market. Therefore, a systematic researches on the whole market demand and supply, market orientation, market structure and enterprise behavior are needed to adapt to the change of market requirement. This is the practical significance of this article.

This article will systematically demonstrate the history of China 's sports nutrition food industry and analyze the factors that influence the development, based on which a strategic thinking on promoting the sports nutrition food industry development will be given, aiming to provide suggestion of reference value to relative department and progression of enterprise.

\section{MATERIAL AND METHODS}

\subsection{Sports Nutrition Food Concept, Function and Classi- fication}

As many other products' development of the concept, the concept of sports nutrition food is also becoming clear in the process of continuous production and development. In China the five industrial standards and one national standard about sports nutrition food all define the sports nutrition food as the specially processed food or nutrition supplements or modulation that can satisfy athletes, exercise group and manual labour's physiological and metabolic needs and the needs of specific nutrients, according to the special formula. This kind of food belongs to the special food, whose nutrient 
composition and content all match physiological demand of the sports population and which has significant difference with ordinary food and health food [1-2].

In terms of the classification of sports nutrition food, it can be classified according to the function of sports nutrition food, and also be classified according to the main components of the sports nutrition food, both means shall be used alone. Therefore, in this paper, the classification of sports nutrition food is combined with the function of sports nutrition food and ingredients, in order to cover the entire sports nutrition food so as to provide comprehensive analysis basis [3-4].

According to what has been issued the sports nutrition food industry standards and national standards, and the development of sports nutrition food industry formats, sports nutrition food can be divided into energy supplement, protein supplement, and energy control.

\subsection{Historical Reviews on China's Sports Nutrition Food Development}

Before the reform and opening up, people's fundamental nutritional requirement is difficult to meet due to the low level of productive force and economy developing level, not to mention the concept and production of nutritious foods. After the reform and opening up, the economy grew rapidly, so did income level.

With the development of foreign trade, some foreign sports nutrition food began to appear. These products mainly came from travellers and overseas students who brought back with curiosity. Foreign enterprises of these productions haven't establish selling department or distribution channel inboard yet. Companies represented by Guangdong Jianlibao beverage factory investigated the trend of foreign sports nutrition food industry development and potential need in China and decided to produce Chinese sports health product. Most of scholars and professionals regard the appearance of Jianlibao as the start point of china's sports nutrition food development [5].

In 1998, CPT company was established, which was the first enterprise combines research and development, production and marketing. It has become the leading enterprise in the field of sports nutrition and also one of the most influential sports brand in China after dozens of year's development.

Meanwhile, the sports nutrition food industry also developed rapidly; market including sports nutrition, sports beverage, and sports conceptual beverage has reached the scale of 1-1.5 billion RMB in 2004. The success of 2008 Beijing Olympic Games left precious Olympic legacy to China. In this context, sports nutrition food market expanded constantly, and sports nutrition food industry grew more maturely. The concept of combining nutrition and sports has been accept basically and has become popular among the young. Even the common people who don't do sports also consume the sports nutrition food to indicate their pursuit of healthy life style. These changes of demand structure show enormous potentiality of this field [6-8].

\subsection{The Market Demand of Sports Nutrition Food Indus-} try

Market demand is the foundation of enterprise survival and development. The development of sports nutrition food industry also need the market demand as the basis, and ultimately formed consumption structure and consumption. Sports nutrition food demand refers to the public demand for sports nutrition food. Sports nutrition food demand put purchase desire as premise and is restricted by the ability to pay. Sports nutrition food requirements can be divided into potential demand and effective demand. Potential demand is people's objective demand for sports nutrition food, including the purchase desire, but affected by the affordability and other factors thus is temporarily suppressed, and the demand without purchase desire; The effective demand of sports nutrition food refers to the current purchase desire, affordability and current demand that can be turned into actual purchasing behaviour. The potential demand of sports nutrition food is the precondition of effective demand, but the potential demand must be transformed into effective demand, and ultimately lead to sports nutrition consumption, which is the basic requirement of sports nutrition food industry development.

The main factors that influence the market demand can be divided in to economic factors and non-economic factors.

Economic factors include: economic development and the income level of resident; the change of residents' consumption structure; Consumption idea and awareness; Consumer preferences; the price of related products; Industrial structure and the sports industry structure, etc.

Economic development and income level: according to the principle of economics, income growth and the growth of consumer demand have positive correlation. In general, the lower people's income level is, the higher the marginal consumption tendency is; the higher the residents' income level is, the lower the marginal consumption tendency is. In the social and economic structure, high earners and low-income account less, while the middle class is the main body, occupying the dormant position, which in the overall population distribution is "featured" structure, thus is advantageous to the growth in consumer demand [9]. China's current population distribution is the bell type structure, that is to say the middle class is less, and high income and low income are relatively more. And with the enlargement of the income gap, wealth is much attributed to a few high earners, but those with much wealth show a low propensity for sports nutrition food average consumption, and the purchasing power is relative excess; while a large number of consumers with potential demand are low and middle income earners. They show a high propensity for sports nutrition food average consumption, but they are seriously short of purchasing power. The inconsistency between the income level and average propensity to consume make it hard to transform the potential demand of the sports nutrition food into effective demand with affordability, resulting in the decreased the average propensity in consumption of sports nutrition food, and the limited total demand, insufficient effective demand.

The change of residents' consumption structure (including diet): With the improvement of people's living standard 
and enhancement of health consciousness, sports nutrition food will gradually become ordinary goods in daily life, and even become necessities. Consumer demand rigidity and expansion of consumer groups increase the market demand, providing a market space for industry development. However, changes in income level, consumption level, consumption structure didn't change the consumption idea and awareness of the residents in our country, which mainly displays in: first, people who take the initiative to participate in physical exercise, especially pay to participate in physical exercise does not increase significantly; second, even the people taking part in physical exercise lack of understanding of the function of sports nutrition food.

Consumer preferences: Consumers' preference of sports nutrition foods is also an important factor influencing the sports nutrition food market demand. The preference is related to sports and physical exercise crowd's understanding of the functions of nutrition and food. In the exercise population of China, many people think that good exercise doesn't require the use of specialized sports nutrition food, while in developed countries it is not the case. Take America as example, people who use sports nutrition food can be divided into four categories: professional sports athletes, amateur sports enthusiasts, bodybuilding enthusiasts, and bodybuilder. the proportion of these four groups in consumption of sports nutrition food are $23 \%, 19 \%, 35 \%, 19 \%$, the proportion of amateur sports and bodybuilding's consumption is $54 \%$, more than half of total consumption, proving that in the United States, whether professional or amateur athletes sports enthusiasts clearly understand the role and advantage of sports nutrition food, and thus consume sports nutrition food for long-term.

The price of sports nutrition food and the price of related products: In economics, related products mainly refer to the complements and substitutes. Complements refer to a kind of commodity's price rising (or falling) can lead to a fall (or increase) in demand of another kind of goods; Substitutes refer to a kind of commodity's price rising (or falling) will lead to another kind of commodity demand increase (or decrease). Related products for sports nutrition food are mainly substitutes, including general health food and traditional food. From the general level of consumption, sports nutrition food price is higher than ordinary food. Therefore, when people haven't form the habit of buying sports nutrition food and sports nutrition food haven't become a necessity, people often hold a misunderstanding in consumption, ignoring the health and nutrition issues and consume common health food and traditional food with prices lower, but the body's main energy haven't got effective supplement.

There are some potential threats from other industry. One is energy drinks. Energy drinks and sports nutrition food usually share some similar functions, and professional sports nutrition is not attractive enough for consumers, while energy drink is not is very important to everyone. Another threat is a protein. With high popularity, more consumers and similar composition, protein powder can be more easily accepted by consumers, so there will be intervention from other field [10].

The impact of the sports industry structure: According to the State General Administration of Sports, the national bu- reau of statistics' statistical bulletin of national sports and related industry of 2009-2010, in the added value of sports and related industries in China, sports supplies, clothing shoes and hats manufacturing and sports venues construction proportion is as high as $70.6 \%$, and sporting goods and clothing shoes and hats, sports organization and management activities, sports venues management activities, sports fitness and leisure activities, sports intermediary activities, sports training and sports lottery and sports industry accounted for only 29. 4\%, as shown in Fig. (1).

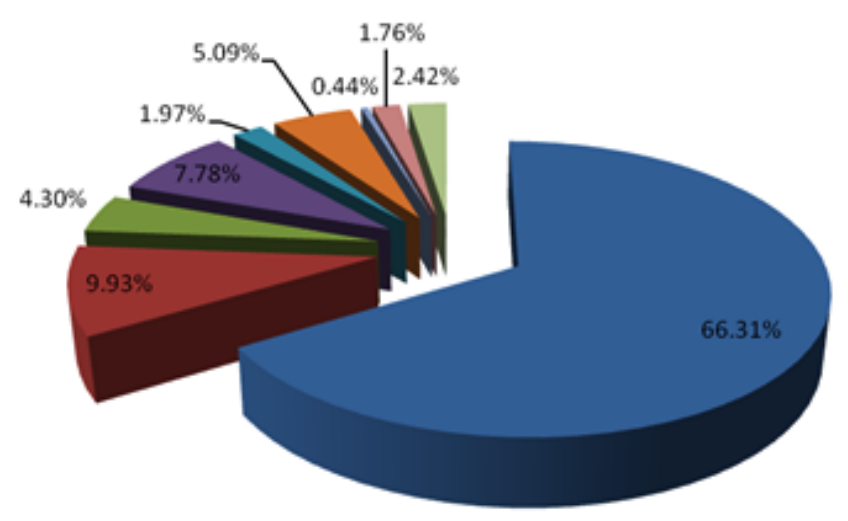

$$
\begin{aligned}
& \text { = Sports supplies, clothing shoes and hats } \\
& \text { manufacturing } \\
& \text { = Sports supplies, clothing shoes and hats } \\
& \text { selling } \\
& \text { m Sports venues construction } \\
& \text { =Sports organization and management activities } \\
& =\text { Sports venuemanagenent activities } \\
& =\text { Sports fitness and leisure activities }
\end{aligned}
$$

Fig. (1). The added value composition of national sports and relative industry.

SOURCE: State eneral administration of sports. The national bureue of statistics. National sports and relative industry statistical bulletin of 2009-2010, 2011.10

This sports industry structure will surely cause adverse effect on sports nutrition food industry market demand. Only by developing sports entertainment industry and sports fitness leisure industry can involve more people to participate in physical exercise, sports nutrition food is likely enter into more people's daily lives, otherwise it becomes like water without source.

Non-economic factors mainly include: the different consumer groups; the number of sports population; Knowledge and sports nutrition food standards and security; Government policy and public opinion, etc.

\subsection{Sports Nutrition Food Development in Western Countries and Inspiration}

From the appearance of competitive sports, athletes always concerns for their diet. But how to make one's diet more scientific can only depend on the results of scientific experiment. The real sports nutrition food with modern significance came out from exercise physiological laboratory. 
The first study on nutrient substance metabolism when human body is doing exercise was originated from Sweden in 1930s when the lab conducted experiments on mechanism of carbohydrate and fat metabolism in the process of sporting. In the end of 1960s, scientists in Scandinavia began to study the mechanism of storage, employment, and synthesis of muscle glycogen during the long process of sporting. In 1965, some scientists in university of Florida leading by Dr. Robert Cade developed the special beverage for their football team, named after the team's mascot-Gatorade9. In 1970s, exercise physiologists from all over the world, especially those from America worked on the study of athletes' exercise physiology. In 1980s, with the increase of competitive sports level and the increase number of people joining sporting, the research on sports nutrition food began to attract the public attention.

The road that western countries take in the development of sports nutrition food provides important inspiration and reference in the development of China's sports nutrition industry.

(1) Production structure should adapt to the consumer demand and market change; market should be subdivided efficiently. The major focus of future product should be the wide spread of products' knowledge among the public, diversified product combination to meet consumers' requirement, increase of composition security, various marketing distribution, improvement and richness of tastes, more organic nutrition, convenience and flexibility of package and cooking, efficiency of the products.

(2) Ability of research and development should be paid attention to increase the core competitiveness. New products, new recipe, new patent with independent intellectual property right need to be created to ensure the market competitive force by means of effective cooperation between research institution and sports team, encourage the participant of society

(3) Relative law system should be improved to establish strict industrial criteria and national criteria and to punish the illegal behavior.

\section{RESULTS AND DISCUSSION}

The sports nutrition food industry in China originated in competitive sports, gradually formed a professional segment market positioning mode, that is to say the current positioning industry as a whole is niche markets. With the development of economy, industry positioning from niche market towards public may have the possibility of market demand.

Through the efforts of the leading enterprises, the technical level of sports nutrition food industry in China have been close to or reached the international advanced level in some ways, but most of the sports nutrition food enterprise in our country still do not have their own core technology, and even some companies only buy the formula of sports nutrition food production and entrusted to other sports nutrition food production enterprises and pharmaceutical companies to do the production. On the whole, our country sports nutrition food industry comprehensive technology level is still low, thus efforts should be made from two aspects of independent innovation and the introduction of absorption and innovation efforts.

As with other industries, brand is the core of sports nutrition food enterprise market competition ability, and one of the decisive factors for enterprise continuing to grow. Therefore, enterprises should establish clear brand awareness and promote the brand influence through effective marketing tool. In addition, as an emerging industry, companies need to spend more energy to promote the new concept of sports nutrition, new technology, letting more consumers accept the new value brought by the new industry. So, sports nutrition food industry enterprises should pay greater attention to the brand strategy, through effective marketing strategy to build brand enterprises.

\section{CONCLUSION}

From the perspective of the market demand and supply of sports nutrition food industry in China: first, the sports nutrition food industry market demand is divided into potential demand and effective demand. The change from Potential demand into effective demand is influenced by economic factors and non-economic factors. Economic factors include: economic development and the income level of resident; The change of residents' consumption structure; Consumption idea and awareness; Consumer preferences; The price of related products; Industrial structure and the sports industry structure, etc. Non-economic factors mainly include: the different consumer groups; the number of sports population; Knowledge and sports nutrition food standards and security; Government policy and public opinion, etc. Overall, at present effective demand of sports nutrition food is insufficient. The main reasons are: people's consumption idea and awareness didn't change, and the number of people's active participation of physical exercise didn't increase; Understanding of the function of sports nutrition food is limited; Food safety regulation is not standard. Second, main factors that impact on China's sports nutrition food industry market supply include: cost and price, marketing channels and marketing tools, research and development investment. The main body in sports nutrition food industry market supply is relatively small. Compared with developed countries, sports nutrition food types, quantity and quality needs to be improved.

From the perspective of the market structure of sports nutrition food industry in our country: first, China's sports nutrition food industry market concentration is higher. Second, there are some barriers to entre sports nutrition food industry in China .As a technology-intensive industry, there are capital barriers, technical barriers and barriers to policies and regulations. Third, the problem of product homogeneity is serious. Our country sports nutrition food differentiation is not big, homogeneity is more serious, mainly in functional repetitive and formula. Fourth, the analysis shows that the market structure of sports nutrition food industry in China belong to the oligopoly market structure. The future development should be monopolistic competition, increasing competition main body, expanding the scale of industry and increasing the technological innovation.

Experience of European and American countries for the development of sports nutrition food industry in China has 
important significance: first, according to consumer demand and the market changes, adjusting the product structure and marketing constantly. Second, paying attention to the research and development capabilities to improve the core competitiveness. Third, the government improves sports nutrition food regulatory system of laws and regulations, and establishes a comprehensive strict industry standards and national standards.

Implement the strategy of transformation: to obtain products and services can be derived from government and health care market therefore industry have possessed the foundation of changing from minority to majority.

Increase the intensity of technological development: On the whole, our country sports nutrition food industry needs to make efforts from two aspects -- independent innovation and re-innovation. Specifically, first, based on the different needs of different groups, companies need to further strengthen product development research, make long-term sustained investment. Second, according to the different needs of different groups, companies need conduct application technology research by putting the solution as the core, especially combine with scientific exercise, reasonable diet and the use of sports nutrition food development research, building perfect sports nutrition health promotion service system platform. Third, companies also need to study and introduce advanced equipment and production equipment, particularly the technique and high level equipment in food safety monitoring.

Brand making: Brand is the core of sports nutrition food enterprise market competition ability, and the decisive factor for a sports nutrition food enterprise's continued growth. Enterprises should attach great importance to brand strategy, through effective marketing strategy to build brand enterprises.

Strengthen the government's supervision, and industry's self-discipline: First, the government must strictly control and standardize the industry standard through strict legislation, law enforcement. Second, nutrition food association's main future jobs are: strengthen the construction of honesty and self-discipline, establish communication platform for enterprises, government and consumers.

\section{CONFLICT OF INTEREST}

The authors confirm that this article content has no conflicts of interest.

\section{ACKNOWLEDGEMENT}

This work is supported by the Key Project of Guangxi Social Sciences, China (No.gxsk201424), the Education Science fund of the Education Department of Guangxi, China (No.2014JGA268), and Guangxi Office for Education Sciences Planning, China (No.2013C108).

\section{REFERENCES}

[1] C. Menard, and G.K.Peter, "Organizational Issues in the Agrifood Sector: Toward a Comparative Approach," American Journal of Agriculture Economics, vol. 86, no.3, pp.750-755, 2004.

[2] D. Pick, "Product Differentiation and Asymmetric Information in Agriculturaland Food Market: Defining the Role for Government: Discussion," American Journal of Agriculture Economics, vol. 85, no.3, pp.742-743, 2003.

[3] D. M. Lambert, K. T. McNamara, and M. I. Garrett, "Food Industry Investment Flows: Implications for Rural Development," The review of regional studies, vol. 36, no.2, pp.140-162, 2006.

[4] G. Hendrikse, and J. Bijman, "Ownership Structure in Agrifood Chains: The Marketing Cooperative," American Journal of Agriculture Economics, vol. 84, no.1, pp. 104-119, 2002.

[5] C.M. Hasler, and A.C. Brown, "Position of the American Dietetic Association: Functional foods," Journal of the American Dietetic Association, vol. 104, no.5, pp. 814-826, 2004.

[6] S. K. Schumacher, "The Persistence of Profitability among Firms in the Food Economy," American Journal of Agriculture Economics, vol. 87, no.1, pp. 103-115, 2005.

[7] A. Fearne, and R. Ray, "Procurement best practice in the food industry: supplier clustering as a source of strategic competitive advantage," Supply Chain Management: An International Journal Supply Chain Management: An International Journal, vol. 8, no.1, pp.12-16, 2003.

[8] S. Henson, "Exploring Incentives for the Adoption of Food Safety Controls: HACCP Implementation in the U.K. Dairy Sector," $A p$ plied economic perspectives and policy, vol. 22, no.2, pp.407-420, 2000.

[9] W. B. Traill, etc. "Imiovation in the food industry," Agribusiness, vol. 18, no.1, pp.1-21, 2002.

[10] V. Wim, "Consumer acceptance of functional foods:sociodemographic, cognitive and attitudinal determinants," Food Quality And Preference, vol. 16, no.1, pp.45-57, 2005.

\begin{tabular}{lcc}
\hline Received: June 10, 2015 & Revised: July 29, 2015 & Accepted: August 15, 2015 \\
C) Huawei Liang; Licensee Bentham Open. &
\end{tabular}

This is an open access article licensed under the terms of the (https://creativecommons.org/licenses/by/4.0/legalcode), which permits unrestricted, noncommercial use, distribution and reproduction in any medium, provided the work is properly cited. 